\title{
Unraveling the mystery of postoperative atrial fibrillation
}

\author{
G. Hossein Almassi, MD
}

See related article on pages 886-92.

Postoperative atrial fibrillation (POAF) continues to be the most common complication after cardiac operations. Despite all the advances in surgical technique, anesthesia, and perioperative care, the incidence of this arrhythmia has remained unchanged during the last 2 decades. ${ }^{1}$ Although POAF is for the most part self-limiting, its impact on both short-term outcomes and long-term mortality is well documented. ${ }^{2,3}$ Still, no effective prophylactic measure is in sight. Prophylactic use of antiarrhythmic agents, pulmonary vein isolation, a posterior pericardial window, and postoperative atrial pacing, have had variable success in lowering the incidence of POAF, but none has demonstrated any impact on the postoperative outcomes or survival. ${ }^{4}$ The literature is replete with various theories about the underlying causes and factors responsible for the genesis of POAF; however, the precise mechanism for its development, its underlying causes, and effective preventive measures remain elusive. Older age appears to be the only consistent factor in most large series. Hypertension, obesity, and race are other risk factors that are also common to nonsurgical atrial fibrillation. ${ }^{5-7}$ The role of cardiopulmonary bypass and the potential mechanisms leading to POAF have long been discussed and reported; however, experience with offpump coronary artery bypass grafting disproved the theories about the role of cardiopulmonary bypass as the major contributing factor in the development of POAF. $^{8}$

The report by Melby and colleagues ${ }^{9}$ in this issue of the Journal is a new look at POAF in the time-related parametric hazard domain. Melby and colleagues ${ }^{9}$ suggest a bimodal hazard for POAF, with distinct risks for each phase that overlap with time. Looking at their data and in line with previous reports on this topic, mitral valve replacement with or without coronary artery bypass

\footnotetext{
From the Department of Cardiothoracic Surgery, Medical College of Wisconsin, Milwaukee, Wis.

Disclosures: G.H.A. receives research nurse salary support from Eli Lilly and Company.

Received for publication Nov 24, 2014; accepted for publication Nov 25, 2014; available ahead of print Dec 19, 2014.

Address for reprints: G. Hossein Almassi, MD, Department of Cardiothoracic Surgery, Medical College of Wisconsin, $9200 \mathrm{~W}$ Wisconsin Ave, Milwaukee, WI 53226 (E-mail: halmassi@mcw.edu).

J Thorac Cardiovasc Surg 2015;149:893 0022-5223/\$0.00

Published by Elsevier Inc. on behalf of The American Association for Thoracic Surgery

http://dx.doi.org/10.1016/j.jtcvs.2014.11.072
}

grafting carries the highest risk for development of POAF. ${ }^{10}$ The risk remains elevated for a longer interval before returning to the baseline. Melby and colleagues' suggestion ${ }^{9}$ for looking into the mechanisms responsible for this behavior is well taken.

Cardiac surgeons and cardiologists continue to be challenged by POAF and its associated increased morbidity and mortality. In our analysis of the causes of death at 1 year in patients enrolled in the Randomized On/Off Bypass (ROOBY) trial (POAF, $\mathrm{n}=551$; no POAF, $\mathrm{n}=1552$ ), most of the deaths in the POAF group $(71.4 \%)$ were cardiac related, with only 1 death secondary to a cerebrovascular accident (unpublished data). Current management strategies for POAF are borrowed mainly from the experience with nonsurgical atrial fibrillation. POAF should be regarded as a distinct entity from nonsurgical atrial fibrillation. Efforts should be directed toward elucidating the basic pathophysiologic mechanisms of POAF, with concurrent initiatives directed toward developing effective prophylactic measures to prevent its occurrence and thus improve patient outcomes.

\section{References}

1. Shen J, Lall S, Zheng V, Buckley P, Damiano RJ Jr, Schuessler RB. The persistent problem of new-onset postoperative atrial fibrillation: a singleinstitution experience over two decades. J Thorac Cardiovasc Surg. 2011; 141:559-70.

2. Filardo G, Hamilton C, Hebeler RF Jr, Hamman B, Grayburn P. New-onset postoperative atrial fibrillation after isolated coronary artery bypass graft surgery and long-term survival. Circ Cardiovasc Qual Outcomes. 2009;2: 164-9.

3. Mariscalco G, Engström KG. Postoperative atrial fibrillation is associated with late mortality after coronary surgery but not after valvular surgery. Ann Thorac Surg. 2009;88:1871-6.

4. Arsenault KA, Yusuf AM, Crystal E, Healey JS, Morillo CA, Nair GM, et al. Interventions for preventing post-operative atrial fibrillation in patients undergoing heart surgery. Cochrane Database Syst Rev. 2013;1: CD003611.

5. Borzecki AM, Bridgers K, Liebschuz JM, Kader B, Kazis LE, Berlowitz DR. Racial differences in the prevalence of atrial fibrillation among males. $J$ Natl Med Assoc. 2008;100:237-45

6. Marcus GM, Olgin JE, Whooley M, Vittinghoff E, Stone KL, Mehra R, et al. Racial differences in atrial fibrillation prevalence and left atrial size. Am J Med. 2010;123:375.e1-7.

7. Echahidi N, Mohty D, Pibarot P, Després JP, O'Hara G, Champagne J, et al. Obesity and metabolic syndrome are independent risk factors for atrial fibrillation after coronary artery bypass graft surgery. Circulation. 2007;116(Suppl 1):I213-9.

8. Almassi GH, Pecsi SA, Collins JF, Shroyer AL, Zenati MA, Grover FL. Predictors and impact of postoperative atrial fibrillation on patients' outcomes: a report from the Randomized On Versus Off Bypass trial. J Thorac Cardiovasc Surg. 2012;143:93-102.

9. Melby SJ, George JF, Picone DJ, Wallace JP, Davies JE, George DJ, et al Time-related parametric risk factor analysis for postoperative atrial fibrillation following heart surgery. J Thorac Cardiovasc Surg. 2015;149:886-92.

10. Almassi GH, Schowalter T, Nicolosi AC, Aggarwal A, Moritz TE, Henderson WG, et al. Atrial fibrillation after cardiac surgery: a major morbid event? Ann Surg. 1997;226:501-11; discussion 511-3. 